\title{
Potential Effect of Physical Activity Calorie Equivalent Labeling on Parent Fast Food Decisions
}

Anthony J. Viera, MD, MPHª, Ray Antonelli ${ }^{b}$

\begin{abstract}
Menu labels displaying food energy in physical activity calorie equivalents (PACE) is a possible strategy to encourage ordering meals with fewer calories and promoting physical activity. Potential effects of such labeling for children have never been examined.

METHODS: We conducted a national survey of 1000 parents randomized to 1 of 4 fast food menus: no labels, calories only, calories plus minutes, or calories plus miles needed to walk to burn the calories. Respondents were asked to imagine they were in a fast food restaurant and place an order for their child. At the survey's conclusion, all respondents were shown a calorie-only label and both PACE labels and asked to rate the likelihood each label would influence them to encourage their child to exercise.

RESULTS: We excluded respondents whose meals totaled 0 calories or $>4000$ calories, leaving 823 parents in the analysis. The mean age of the child for whom the meal was "ordered" was 9.5 years. Parents whose menus displayed no label ordered an average of 1294 calories, whereas those shown calories only, calories plus minutes, or calories plus miles ordered 1066, 1060, and 1099 calories, respectively $(P=.0001)$. Only 20\% of parents reported that caloriesonly labeling would be "very likely" to prompt them to encourage their children to exercise versus 38\% for calories plus minutes $(P<.0001)$ and $37 \%$ for calories plus miles $(P<.0001)$. concLusions: PACE labeling may influence parents' decisions on what fast food items to order for their children and encourage them to get their children to exercise.
\end{abstract}

WHAT'S KNOWN ON THIS SUBJECT: Menu labels depicting physical activity calorie equivalents may lead to ordering of fast food meals totaling fewer calories for adults. The effects of physical activity calorie equivalent labeling on parents' fast food decisions for their children have not been examined.

WHAT THIS STUDY ADDS: Parents shown menus with any type of caloric content label may order fast food meals totaling fewer calories for their children. Menu labels showing physical activity equivalents may be more likely to influence parents to encourage their children to exercise.
${ }^{a}$ Department of Family Medicine, and ${ }^{b}$ School of Medicine, University of North Carolina, Chapel Hill, North Carolina Dr Viera conceptualized and designed the study, analyzed the data, and drafted the initial manuscript; Mr Antonelli assisted with design of the study, drafted the questionnaire, oversaw data collection and coding, helped interpret the data, and critically reviewed the manuscript; and both authors approved the final manuscript as submitted and agree to be accountable for all aspects of the work.

www.pediatrics.org/cgi/doi/10.1542/peds.2014-2902

DOI: $10.1542 / p e d s .2014-2902$

Accepted for publication Nov 11, 2014

Address correspondence to Anthony J. Viera, MD, MPH, Department of Family Medicine, University of North Carolina at Chapel Hill, 590 Manning Dr, CB 7595, Chapel Hill, NC 27599. E-mail: anthony_viera@med. unc.edu

PEDIATRICS (ISSN Numbers: Print, 0031-4005; Online, 1098-4275).

Copyright @ 2015 by the American Academy of Pediatrics

FINANCIAL DISCLOSURE: The authors have indicated they have no financial relationships relevant to this article to disclose.

FUNDING: This work was supported by funds from the endowed Charles B. Wilkerson, MD, '06 Distinguished Professorship of Family Medicine and by grant T35-DK007386 from the National Institutes of Health. Funded by the National Institutes of Health (NIH)

POTENTIAL CONFLICT OF INTEREST: The authors have indicated they have no potential conflicts of interest to disclose. 
Childhood obesity is highly prevalent in the United States. In 2009-2010, nearly 1 in 3 US children aged 2 to 19 years was overweight or obese, and 1 in 6 was obese. ${ }^{1}$ Children and teens who are obese tend to remain obese into adulthood, and childhood obesity is associated with adverse health outcomes in adulthood. ${ }^{2-4}$ Preventing childhood obesity is thus an important strategy to prevent adult obesity.

Physical activity is an important component of childhood obesity prevention. The US Department of Health and Human Services recommends that children and adolescents aged 6 to 17 years engage in at least 60 minutes of physical activity each day. ${ }^{5}$ Similarly, the American Heart Association recommends that all children age 2 years and older should participate in at least 60 minutes of developmentally appropriate and varied, moderate-intensity physical activities every day or have at least two 30-minute periods or four 15-minute periods in which they can engage in vigorous activities appropriate to their age, gender, and stage of physical and emotional development. 6 Unfortunately, only $42 \%$ of 6 - to 11 -year-olds and only $8 \%$ of 12 - to 15 -year-olds approach this level of physical activity. ${ }^{7}$

Further contributing to childhood obesity is the fact that calories consumed at restaurants make up about one-third of the average American's diet. ${ }^{8}$ Fast food consumption is particularly common among children and contributes to high fat and caloric intake. ${ }^{9}$ Public health policymakers have consequently sought new ways to decrease caloric intake for both adults and children. Menu labeling is one approach that has received widespread acceptance following the Affordable Care Act's mandate that restaurants with $>20$ locations must post calorie counts. ${ }^{10}$

Despite their growing use, however, calorie labels on menus may not be the most effective way to express food energy content to consumers. Studies report conflicting results in the ability of calorie-labeled menus to reduce caloric consumption in realworld settings. ${ }^{11,12}$ Calorie labels do not appear to significantly reduce the number of calories consumed in a meal, a trend that appears to occur in adolescents as well as adults. ${ }^{13}$ In fast food restaurants, consumers may have insufficient time to weigh various meal options based on caloric content, whereas others may lack the health literacy needed to use calorie-based nutrition information. ${ }^{14}$ Some consumers may not understand what calories represent whereas others may lack the numeracy skills to apply calorie content of a food item to understanding the fraction of total calories consumed in a day. The little research that exists on the effect of calorie labeling on parents' choices for their children suggests no effect, although a hypothetical scenario study suggested that parents might order fewer calories for their children when a menu is labeled with calorie information. ${ }^{15,16}$ Overall, though, it seems consumers may not know how to use calorie information to guide food ordering for themselves or for their children.

Labels that depict the physical activity required to expend the calories in a food item might be easier to understand and potentially more effective. We previously developed physical activity calorie expenditure (PACE) labels and examined their potential influence on adults' fast food decisions. ${ }^{17,18}$ In a randomized trial using hypothetical scenarios, we found that those shown fast food labels depicting calories and miles to walk to burn those calories ordered on average about 100 fewer calories than when shown calorie information alone. ${ }^{18}$ To our knowledge, no research has examined whether PACE labeling might influence parents' decisions about what foods they purchase for their children. Because physical activity equivalent labels might theoretically also influence decisions to exercise, exploration of whether such an effect may translate to parental influence on children's behavior also is worth exploring. In this study, we examined whether parents shown PACE labels might order fewer fast food calories for their children. Because PACE labels also might work by motivating physical activity, we also explored whether they might influence parents to encourage their children to get more exercise.

\section{METHODS}

\section{Overall Design}

We conducted a national crosssectional study by using a Web-based survey administered through Survey Sampling International (SSI). It was granted exempt status by the institutional review board of the University of North Carolina. Our survey consisted of a hypothetical complete fast food menu identical to the menu used in a previous study. ${ }^{18}$ Briefly, the menu items shown to participants were chosen to represent generic items that are available at fast food restaurants nationwide. We included no brand names except in the labels for Coke, Diet Coke, and Sprite.

Participants were randomized to 1 of 4 labels for the menu items: no label, calories only, calories plus minutes to walk to burn the calories in the food item, or calories plus miles to walk to burn the calories in the food item. A registered dietician reviewed the menu, along with caloric content and the number of miles and minutes needed to burn off the calories in each item, calculations based on a 160-pound adult walking 2 miles per hour. We asked respondents to imagine they were in a fast food restaurant and to place an order for their child using the displayed menu. At the end of the survey, all respondents were asked to rate (5-point scale from "very unlikely" to "very likely") the likelihood that each type of menu 
label would influence (1) their fast food ordering for their child, and (2) their potential to motivate their child to get some exercise.

\section{Participant Selection}

Participants were recruited in the summer of 2014 by using SSI. Our only eligibility criteria were age 18 years or older, parent of at least 1 child ages 2 to 17 years, and had to have eaten at a fast food restaurant in the past month. SSI recruited participants via E-mail invitation to preexisting participant panels and by banner advertisements posted to online communities, social networks, and Web sites. Potential participants were digitally fingerprinted and checked against third party databases to ensure each respondent was unique. As a quality assurance measure, respondents who completed the survey in in less than one-third of the median response time were not included. Per usual SSI policy, respondents were offered a small cash reward, such as $\$ 0.50$ to $\$ 1.00$, or entry into sweepstakes for prize drawings.

\section{Outcome Variables}

Our main outcome variable was total calories that parents ordered for their child. We also examined total calories ordered as "burgers" (including all sandwich types), sides (eg, French fries), drinks, and desserts.

\section{Additional Variables}

We assessed basic demographics of respondents. Parents were asked to report their height and weight, which were used to calculate their BMI. Parents also were asked whether their child was overweight with response options of yes, no, or not sure. We also assessed health literacy by using the Newest Vital Sign, which has been validated in multiple studies. ${ }^{19}$ Health literacy was deemed "adequate" if respondents answered at least 4 items correctly. Otherwise, health literacy was considered low/ marginal. We asked parents about exercise frequency and collected information about the child for whom the fast food meal was "ordered."

TABLE 1 Characteristics of Study Sample, $n=823$

\begin{tabular}{|c|c|c|c|c|c|c|}
\hline & $\begin{array}{c}\text { All, } \\
n=823\end{array}$ & $\begin{array}{c}\text { No Label, } \\
n=189\end{array}$ & $\begin{array}{c}\text { Calories } \\
\text { Only, } n=209\end{array}$ & $\begin{array}{c}\text { Calories }+ \\
\text { minutes, } n=213\end{array}$ & $\begin{array}{c}\text { Calories }+ \\
\text { miles, } n=212\end{array}$ & $P$ \\
\hline Age, mean (SD) & $38(9.8)$ & $38(9.7)$ & $38(10)$ & $39(10)$ & $39(9.6)$ & .48 \\
\hline Women, \% & 72 & 77 & 72 & 66 & 76 & .048 \\
\hline \multicolumn{7}{|l|}{ Race/ethnicity, \% } \\
\hline Black & 10 & 13 & 13 & 8.1 & 6.7 & \multirow[t]{4}{*}{.07} \\
\hline White & 72 & 64 & 73 & 73 & 75 & \\
\hline Hispanic & 8.6 & 10 & 7.2 & 10 & 6.7 & \\
\hline Other & 9.7 & 13 & 6.7 & 8.1 & 11 & \\
\hline \multicolumn{7}{|l|}{ Education level, \% } \\
\hline At least some high school & 21 & 19 & 25 & 22 & 17 & \multirow[t]{3}{*}{.29} \\
\hline At least some college & 64 & 64 & 61 & 61 & 70 & \\
\hline Graduate degree & 15 & 17 & 14 & 17 & 13 & \\
\hline \multicolumn{7}{|l|}{ Health literacy level, \% } \\
\hline Adequate & 55 & 49 & 56 & 59 & 56 & \multirow[t]{2}{*}{.19} \\
\hline Low/marginal & 45 & 51 & 44 & 41 & 44 & \\
\hline \multicolumn{7}{|l|}{ Total yearly income } \\
\hline$<\$ 35000$ & 26 & 24 & 26 & 25 & 30 & \multirow[t]{3}{*}{.62} \\
\hline$\$ 35000-\$ 50000$ & 42 & 42 & 41 & 46 & 37 & \\
\hline$>\$ 50000$ & 32 & 34 & 33 & 29 & 33 & \\
\hline \multicolumn{7}{|l|}{ Parent BMI category, \% } \\
\hline Normal & 40 & 46 & 40 & 37 & 38 & \multirow[t]{3}{*}{.14} \\
\hline Overweight & 31 & 34 & 28 & 30 & 32 & \\
\hline Obese & 29 & 20 & 32 & 33 & 29 & \\
\hline Days per mo at least $30 \mathrm{~min}$ of exercise & $9.9(9.1)$ & $9.1(8.8)$ & $10(9.1)$ & $9.6(9.0)$ & $11(9.4)$ & .40 \\
\hline \multicolumn{6}{|l|}{ Age group of child for whom meal was "ordered," y } & \multirow[t]{4}{*}{.03} \\
\hline $2-6$ & 33 & 41 & 35 & 28 & 30 & \\
\hline $7-12$ & 34 & 24 & 38 & 37 & 36 & \\
\hline $13-17$ & 33 & 34 & 27 & 34 & 34 & \\
\hline Mean age in years of child for whom meal was "ordered" (SD) & $9.5(4.6)$ & $9.2(5.0)$ & $9.2(4.3)$ & $9.9(4.5)$ & $9.8(4.5)$ & .20 \\
\hline Gender of child for whom meal was "ordered," \% boys & 54 & 56 & 55 & 53 & 53 & .93 \\
\hline Reports child for whom meal was "ordered" is overweight, \% & 9 & 7.4 & 7.2 & 12 & 10 & .33 \\
\hline Average $d /$ wk fast food ordered for child for dinner & $1.3(1.3)$ & $1.4(1.4)$ & $1.2(1.3)$ & $1.3(1.3)$ & $1.2(1.2)$ & .34 \\
\hline Average $\mathrm{d} /$ wk fast food ordered for child for snack & $0.72(1.3)$ & $0.93(1.5)$ & $0.77(1.4)$ & $0.64(1.2)$ & $0.57(1.0)$ & .02 \\
\hline \multicolumn{7}{|l|}{ Region of country, \% } \\
\hline West & 25 & 24 & 23 & 26 & 25 & \multirow[t]{4}{*}{.33} \\
\hline Midwest & 22 & 15 & 22 & 24 & 25 & \\
\hline South & 36 & 40 & 39 & 34 & 32 & \\
\hline Northeast & 17 & 21 & 16 & 15 & 18 & \\
\hline
\end{tabular}


TABLE 2 Fast Food Calories Parents "Ordered" for Their Children

\begin{tabular}{|c|c|c|c|c|c|c|}
\hline & All, $n=823$ & $\begin{array}{l}\text { No label, } \\
n=189\end{array}$ & $\begin{array}{c}\text { Calories only, } \\
n=209\end{array}$ & $\begin{array}{c}\text { Calories + minutes, } \\
n=213\end{array}$ & $\begin{array}{c}\text { Calories + miles, } \\
n=212\end{array}$ & $P$ \\
\hline Total calories & 1125 & 1294 & $1066^{\star}$ & $1060^{\star \star}$ & $1099 \star \star \star$ & .0001 \\
\hline For children 2-6 & 944 & 1088 & 887 & 866 & 902 & $<.0001$ \\
\hline For children $7-12$ & 1088 & 1208 & 1088 & 1076 & 1028 & .11 \\
\hline For children $>12$ & 1336 & 1561 & 1256 & 1172 & 1355 & .002 \\
\hline Parents with adequate health literacy & 1032 & 1157 & 997 & 977 & 1027 & .07 \\
\hline Parents with low/marginal health literacy & 1241 & 1423 & 1155 & 1180 & 1192 & .01 \\
\hline For parents with $\mathrm{BMl}<30 \mathrm{~kg} / \mathrm{m}^{2}$ & 1145 & 1291 & 1067 & 1079 & 1138 & $<.0001$ \\
\hline For parents with $\mathrm{BMI} \geq 30 \mathrm{~kg} / \mathrm{m}^{2}$ & 1034 & 1243 & 1024 & 987 & 969 & .02 \\
\hline Burger calories & 335 & 378 & 316 & 318 & 333 & .01 \\
\hline Side calories & 272 & 287 & 269 & 268 & 264 & .32 \\
\hline Drink calories & 231 & 260 & 226 & 223 & 220 & .20 \\
\hline Dessert calories & 199 & 259 & 188 & 162 & 195 & .0007 \\
\hline
\end{tabular}

Pairwise comparisons to no label: ${ }^{\star} P=.001 ;{ }^{\star \star} P<.001 ;{ }^{\star \star \star} P=.006$.

\section{Data Analysis}

Respondents who ordered a meal totaling 0 calories for themselves or for their children, or $>4000$ calories for themselves or for their children were excluded from analysis because such responses implied lack of understanding of the survey or carelessness in response. For the remaining respondents, we report mean or percent for variables overall and across the 4 menu types. We compared total calories as well as meal component calories across menu types and tested for significance by using analysis of variance. We compared the percentage of parents reporting various levels of potential influence of PACE labels on meal ordering for their children and for prompting parents to encourage children to exercise. Finally, we examined the influence of PACE labels stratified by health literacy. Analyses were conducted by using Stata software (Stata Corp, College Station, TX).

\section{RESULTS}

\section{Characteristics of Respondents}

A total of 1552 E-mail invitations were sent by SSI to potentially eligible participants, of which 1545

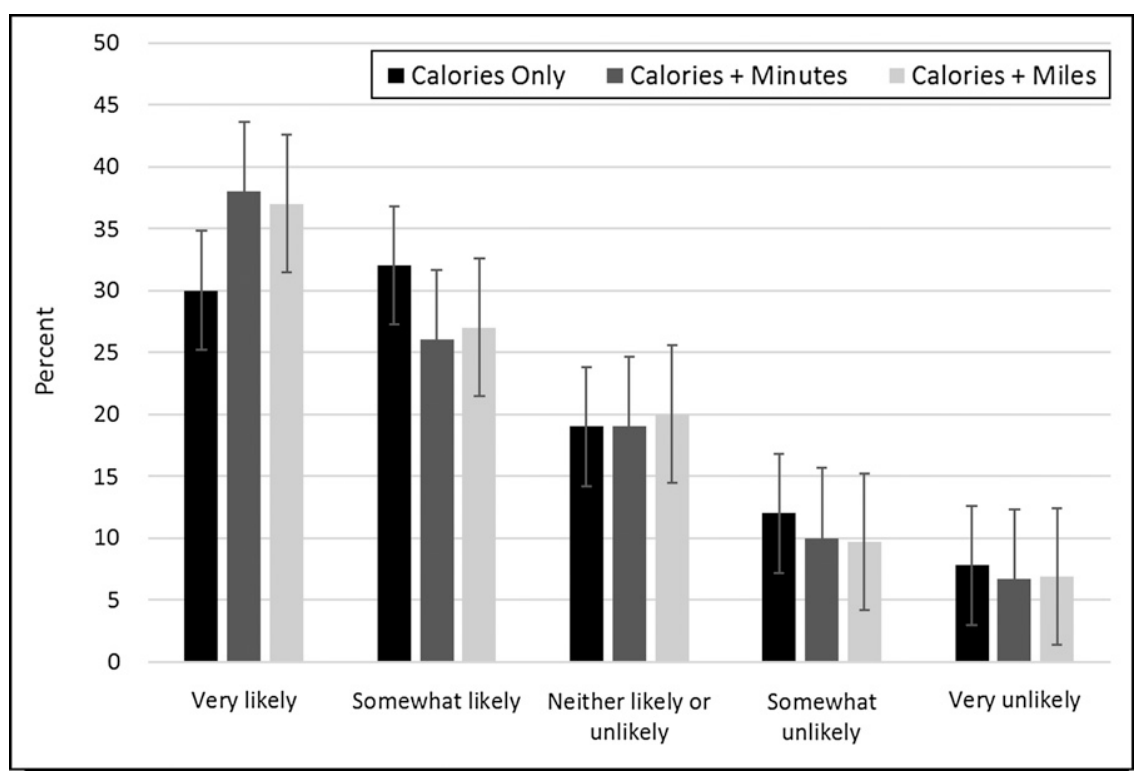

FIGURE 1

Reported potential influence of PACE labels on parents' fast food meal choice for children, overall.

were opened. A total of 544 people were screened out for 1 of the following: not fulfilling eligibility criteria $(n=370)$, hitting a closed quota $(n=64)$, or attempted survey on an unsupported device $(n=9)$. of the 1101 eligible respondents remaining, 2 dropped out on their own after the introduction, 94 dropped out on their own at some other point in the survey, and 5 were classified as "speeders." Thus, our adjusted response rate was 1000 (91\%) of 1101. After excluding respondents who ordered a meal totaling 0 calories for themselves $(n=4)$ or for their children $(n=7)$, or $>4000$ calories for themselves ( $n=155)$ or for their children $(n=11)$, a total of 823 respondents were included in this analysis, randomized to a no-label menu $(n=189)$, calories-only menu $(n=209)$, calories plus minutes $(n=213)$, or calories plus miles $(n=212)$. The mean age of respondents was 38 and similar across groups (Table 1). Approximately $60 \%$ of respondents were overweight or obese. Most respondents were women $(72 \%)$ and white (72\%). Approximately 79\% of respondents had at least some college education; however, health literacy was measured as adequate in only $55 \%$.

The mean age of the child for whom the parent placed a hypothetical food order was 9.5 years (Table 1). Only $9 \%$ of parents reported their child as 
TABLE 3 Percentage of Parents Reporting Potential Influence of PACE Labels on Their Fast Food Meal Choice for Children and to Encourage Children to Exercise, Stratified by Health Literacy Level

\begin{tabular}{llccc}
\hline & & $\begin{array}{c}\text { Low/marginal } \\
\text { health literacy, } \%\end{array}$ & $\begin{array}{c}\text { Adequate } \\
\text { health literacy, \% }\end{array}$ & $P$ \\
\hline Influence fast food meal choice & Calories only & 56 & 67 & .001 \\
& Calories + minutes & 57 & 70 & $<.0001$ \\
& Calories + miles & 58 & 68 & .002 \\
Encourage child to exercise & Calories only & 48 & 50 & .47 \\
& Calories + minutes & 56 & 70 & $<.0001$ \\
& Calories + miles & 57 & 69 & $<.0001$ \\
\hline
\end{tabular}

Potential influence $=$ somewhat likely or very likely.

overweight. On average, parents reported ordering fast food for their children for dinner 1.3 days per week and less than once per week for a snack.

\section{Calories Ordered for Children}

Overall, the average meal parents selected for their child totaled 1125 calories (Table 2). For children 2 to 6 years of age, meals totaled an average of 944 calories, whereas for teenage children, meals averaged 1336 calories. Meal calories also differed by parental health literacy status, with those having adequate health literacy ordering fewer total calories (1032 vs 1241, $P<.0001$ ).

Parents whose menus displayed no label ordered an average of 1294 calories for their child's meal, whereas those shown any label ordered approximately 200 fewer average calories $(P=.0001)$ for their children (Table 2). Overall, the total calories ordered were not statistically significantly different among the 3 labels. The patterns were similar when stratified by age group of the child or BMI category of the parent. Calorie differences were mostly due to differences in burger and dessert calories.

\section{Reported Potential Influence of PACE Labels on Fast Food Meal Choice}

Among the entire sample $(n=823)$, $30 \%$ of parents reported that calories-only labeling would be very likely to influence their selection of fast food for their children (Fig 1). Labels with physical activity equivalents, regardless of whether shown in minutes or miles appeared

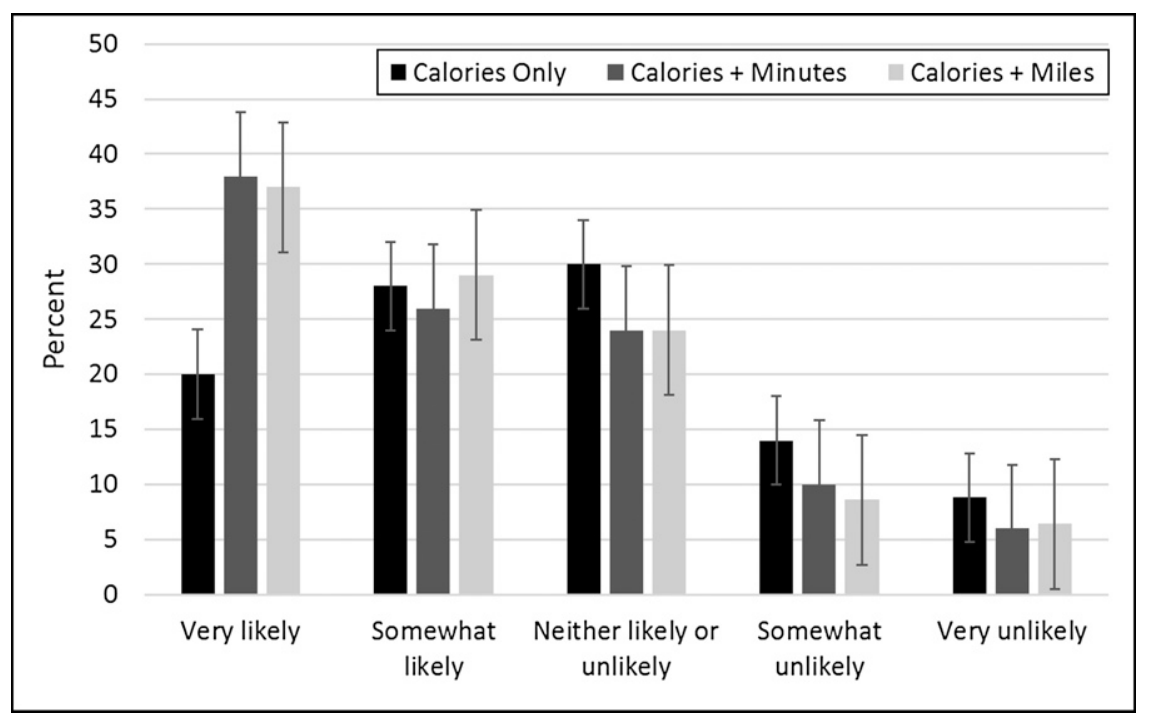

FIGURE 2

Reported potential influence of PACE labels on parents to encourage children to exercise, overall. slightly more influential at the "very likely" end of the scale.

The potential influence of labels varied by health literacy status. A greater percentage of parents with adequate health literacy reported that labels, regardless of whether caloriesonly or calories plus physical activity equivalents, would at least be somewhat likely to influence their meal selection for their children (Table 3).

\section{Reported Potential Influence of PACE Labels on Encouraging Children to Exercise}

Among the entire sample, 20\% of parents reported that calories-only labeling would be very likely to prompt them to encourage their children to exercise (Fig 2). Labels with physical activity equivalents, regardless of whether shown in minutes or miles were significantly more influential at the very likely end of the scale, with calories plus minutes rated as such by 38\% and calories plus miles rated as such by $37 \%$ ( $P<.0001$ for each compared with calories only).

\section{DISCUSSION}

To our knowledge, this study is the first to examine the potential effect of PACE labeling on parental decisions for their children. Our main findings are that (1) parents may be ordering single meals for their children at fast food restaurants that total $>1000$ calories, (2) parents shown any type of label that displays calorie information may order a fast food meal for their child totaling fewer calories, (3) labels showing physical activity equivalents may prompt parents to encourage their children to exercise, and (4) labels showing physical activity equivalents may be more influential in promoting parents' encouragement of their children to exercise among parents with adequate health literacy.

We previously examined the potential influence of PACE labels on a sample 
of adults and found that those shown physical activity equivalents in miles (to walk) ordered on average about 100 fewer calories compared with those shown calories only from the same hypothetical menu used in this study. ${ }^{18}$ In that study, we found little difference in calories ordered when shown physical activity equivalents in minutes (to walk) compared with calories alone. Similar to the present findings, any label displaying caloric information (ie, with or without a physical activity equivalent) seemed to be influential on hypothetical fast food decisions.

Our finding that parents order fewer calories for their children in a hypothetical scenario when shown calorie labeling is similar to the finding of a previous study in which 99 parents of 3- to 6-year-olds were randomized to a McDonald's menu with or without calorie labeling. ${ }^{15}$ Parents shown the menu with calories ordered an average of 102 fewer calories for their children. In a study of actual calories purchased by parents for their 6- to 11-year-old children in a calorie-labeled county versus a non-calorie-labeled county, however, no difference between counties was seen. ${ }^{16}$

Children's physical activity is hindered by "screen time," and parents may not realize the amount of exercise children need to be healthy and to provide some "balance" to the amount of calories they eat. In our study, PACE labels were more effective than calorie-only labels in at least getting parents to think about encouraging their children to exercise more. Whether this potential effect of PACE labeling would translate to a real-world effect remains to be investigated, but a simple populationlevel intervention that potentially can get children to eat less and move more could make a tremendous impact.

To be an effective public health intervention, a labeling scheme has to be easily understood. We hypothesized that calorie labeling may have differential effects based on people's health literacy and numeracy levels. Indeed, we noted that labeling seemed to exert its effect on respondents with low/marginal health literacy and not as much among parents with adequate health literacy. Interestingly, though, more parents with adequate health literacy felt that any of the labels would be helpful in influencing fast food meal choices. This difference might be because parents with higher health literacy are already more careful about what they order for their children and there is a reporting bias. The PACE labels seemed to have a differential effect on reported likelihood of motivating parents to encourage their children to exercise, appearing more influential among the parents with adequate health literacy.

Strengths of this study include its large national sample of participants and the randomization of parents to each of the 4 menu versions. The greatest limitation of our study is that we used a hypothetical scenario that cannot truly substitute for the actual experience of ordering food for a child at a fast food restaurant or for measuring ability to motivate parents to encourage their children to exercise. It is worth noting that any measurement bias would be expected to be nondifferential given the randomization to the menu types.

We did not display the cost of the fast food items, which could influence food-ordering behavior. However, pricing at fast food restaurants is low and therefore unlikely to be a barrier. We also did not include specific "children's" items, such as prepackaged combination meals, on the hypothetical menu. It is possible that parents would have ordered fewer total calories for their children if such items were included. Finally, our labels were not tailored to children. Rather, they were designed for adults. However, we were interested in whether such labels could translate to an effect for children because, especially for young children, adults are responsible for ordering their food. Finally, we did not compare physical activity equivalent labeling by itself (ie, without listing calories as well) to calories alone and to no label, but this comparison would be worth future testing.

\section{CONCLUSIONS}

PACE labels may influence parents' decisions on what fast food items to order for their children and, uniquely, encourage them to try to get their children to exercise. The potentially resulting combination of fewer calories consumed with greater physical activity could help begin to curb childhood obesity. Real-world research is needed to evaluate the effects of PACE labeling for adults and children.

\section{REFERENCES}

1. Ogden $\mathrm{CL}$, Carroll MD, Kit BK, Flegal KM. Prevalence of obesity and trends in body mass index among US children and adolescents, 1999-2010. JAMA. 2012; 307(5):483-490

2. Serdula MK, Ivery D, Coates RJ, Freedman DS, Williamson DF, Byers T. Do obese children become obese adults? A review of the literature. Prev Med. 1993;22(2):167-177

3. Singh AS, Mulder C, Twisk JW, van Mechelen W, Chinapaw MJ. Tracking of childhood overweight into adulthood: a systematic review of the literature. Obes Rev. 2008;9(5):474-488

4. Inge TH, King WC, Jenkins TM, et al. The effect of obesity in adolescence on adult health status. Pediatrics. 2013;132(6): 1098-1104

5. U.S. Department of Health and Human Services. 2008 Physical Activity Guidelines for Americans. Washington, DC: U.S. Department of Health and Human Services; 2008

6. American Heart Association. The AHA's recommendations for physical activity in children. Available at: www.heart.org/ 
HEARTORG/GettingHealthy/HealthierKids/ ActivitiesforKids/The-AHAs-

Recommendations-for-Physical-Activityin-Children_UCM_304053_Article.jsp.

Accessed September 8, 2014

7. Troiano RP, Berrigan D, Dodd KW, Mâsse LC, Tilert T, McDowell M. Physical activity in the United States measured by accelerometer. Med Sci Sports Exerc. 2008;40(1):181-188

8. Variyam J. Nutrition Labeling in the FoodAway-From-Home Sector. An Economic Assessment. Economic Research Report No. (ERR-4) p. 28. April 2005. Available at: www.ers.usda.gov/media/865902/ err4_002.pdf. Accessed December 3, 2014

9. Paeratakul S, Ferdinand DP, Champagne CM, Ryan DH, Bray GA. Fast-food consumption among US adults and children: dietary and nutrient intake profile. J Am Diet Assoc. 2003;103(10): 1332-1338
10. US Food and Drug Administration. Food labeling; nutrition labeling of standard menu items in restaurants and similar retail food establishments. Fed Regist. 2011;76(66): 19191-19236

11. Harnack LJ, French SA. Effect of point-of purchase calorie labeling on restaurant and cafeteria food choices: a review of the literature. Int J Behav Nutr Phys Act. 2008;5(51):51

12. Swartz JJ, Braxton D, Viera AJ. Calorie menu labeling on quick-service restaurant menus: an updated systematic review of the literature. Int $J$ Behav Nutr Phys Act. 2011;8:135

13. Elbel B, Gyamfi J, Kersh R. Child and adolescent fast-food choice and the influence of calorie labeling: a natural experiment. Int $J$ Obes (Lond). 2011; 35(4):493-500

14. Blumenthal K, Volpp KG. Enhancing the effectiveness of food labeling in restaurants. JAMA. 2010;303(6):553-554
15. Tandon PS, Zhou C, Chan NL, et al. The impact of menu labeling on fast-food purchases for children and parents. $A m$ J Prev Med. 2011;41(4):434-438

16. Tandon PS, Wright J, Zhou C, Rogers CB, Christakis DA. Nutrition menu labeling may lead to lower-calorie restaurant meal choices for children. Pediatrics. 2010;125(2):244-248

17. Swartz JJ, Dowray S, Braxton D, Mihas P, Viera AJ. Simplifying healthful choices: a qualitative study of a physical activity based nutrition label format. Nutr $\mathrm{J}$. 2013; $12: 72$

18. Dowray S, Swartz JJ, Braxton D, Viera AJ. Potential effect of physical activity based menu labels on the calorie content of selected fast food meals. Appetite. 2013; 62:173-181

19. Weiss BD, Mays MZ, Martz W, et al. Quick assessment of literacy in primary care: the newest vital sign. Ann Fam Med. 2005;3(6):514-522 